\title{
Concentrations and regularities of disperse-phase distribution of organochlorine pesticides, polychlorinated biphenyls and polycyclic aromatic hydrocarbons in natural water
}

\author{
Mikhail V. Milyukin * and Maksym V. Gorban \\ A.V. Dumansky Institute of Colloid Chemistry and Water Chemistry of National Academy of Sciences of \\ Ukraine, Kyiv, Ukraine
}

\begin{abstract}
This article presents the monitoring results of organochlorine pesticides (OCPs), polychlorinated biphenyls (PCBs), and polycyclic aromatic hydrocarbons (PAHs) in surface water of the Dnieper River for the period 2011-2019. Total levels of OCPs, PCBs and PAHs consist of 1,4-17,1; 2,8-57,2; and 7,5-378,6 ng/L, respectively. A significant increase in pollution levels was not identified. Research results of the disperse-phase distribution of these substances in water were also provided. Less than half of the total contents of pollutants were in the water phase. Average water-soluble parts of OCPs, PCBs, and PAHs accounted for 32, 42, and $44 \%$, respectively. It was shown that water-soluble parts of individual pollutants decrease with the increase in the coefficients of hydrophobicity of compounds. The clearest reliable, relevant correlation between water-soluble parts of individual congeners and coefficients of hydrophobicity was obtained for PCBs.
\end{abstract}

Keywords: OCPs; PCBs; PAHs; surface water; the Dnieper River; monitoring; SPM; coefficient of hydrophobicity.

\section{Introduction}

Organochlorine pesticides (OCPs), polychlorinated biphenyls (PCBs), and polycyclic aromatic hydrocarbons (PAHs) are organic compounds that are characterized by extremely high toxicity, bioavailability (bioaccumulation, bioconcentration, biomagnification) ${ }^{1,2}$ and persistency in the environment. In terms of toxicity OCPs and PCBs are close to polychlorinated dibenzo-p-dioxins (PCDDs) and dibenzofurans (PCDFs) that are considered to be the most hazardous substances on our planet.

OCPs were widely used as contact broad-spectrum insecticides. They were utilized to control infections carried by insects (malaria, typhoid) and agriculture. At present, the use of these compounds is significantly limited.

The main sources of penetration of PCBs into the environment are spills from transformers, capacitors, hydraulic systems, fumes from varnishes, paints, plastics containing PCBs; emissions from the combustion of industrial and communal waste; pesticides with contaminants of PCBs.

PAHs enter into the environment due to incomplete combustion of organic matter. There are natural and anthropogenic sources of PAH emissions. Natural ones are forest fires and volcanic processes; anthropogenic ones include the combustion of coal,

*Corresponding author: Mikhail V. Milyukin

Email address: $m$ milyukin@ukr.net

DOI: http://dx.doi.org/10.13171/mjc10902011211519mvm firewood, gas, household, industrial waste, car exhaust gases, cigarette smoke, and oil leakage. The sources of supply of organic ecotoxicants in Ukraine are not unique ${ }^{3}$.

In order to protect human health and the environment in 2001 at the United Nations conference, the Stockholm Convention on Persistent Organic Pollutants (POPs) was adopted. OCPs, PCBs, PCDDs, and PCDFs were included in the initial list of POPs. Parties to the Convention committed to prevent or restrict the production of POPs, safely dispose of their residues and monitor these compounds in the environment, including natural water systems ${ }^{4}$.

There are many other chemical substances with POPslike characteristics. PAHs belong to a group of these substances. US Environmental Protection Agency, USEPA, encourages monitoring in the environment 16 priority PAHs. Benzo(a)pyrene and dibenzo(a,h) anthracene are the most toxic compounds of this group ${ }^{5}$. Benzo(a)pyrene has carcinogenic, mutagenic, embryotoxic, hematoxic effects ${ }^{6}$.

OCPs, PCBs, and PAHs are characterized by a high coefficient of hydrophobicity, low water solubility, and limited volatility ${ }^{7-14}$. Their physical and chemical properties are presented in detail in Table 1 . Accordingly, in natural water systems, they may exist in different physical forms: in the water-soluble state,

Received July 21, 2020

Accepted September 17, 2020

Published January 4, 2020 
in an associated state with suspended particles, in a solubilized state with organic compounds, including humic and fulvic acids, and surfactants. These physical forms of POPs are different in their levels of bioavailability. Thus, it is essential to establish the distribution of toxicants between specific physical and chemical forms.

The data on the disperse-phase distribution of POPs can be used to develop useful technologies for water treatment. A significant part of organic ecotoxicants can be removed from the water, provided that coagulants and flocculants at the stage of water treatment were correctly chosen.
Owing to the high ecological burden, the problem of POPs is relevant for Ukraine. As a result of the complexity and high cost of identifying POPs, determining these compounds is covered by a limited number of scientists. Therefore information about the concentration of POPs in natural water systems of Ukraine is little. Some investigation results of POPs in objects of Ukrainian water systems are presented in the monograph by Milyukin and Goncharuk ${ }^{3}$. The data of the monitoring of individual OCPs, PCBs, and PAHs in the Dnieper River over the 1990s are provided in papers ${ }^{15-18}$.

Table 1. Physical and chemical properties of OCPs, PCBs, and PAHs.

\begin{tabular}{|c|c|c|c|c|}
\hline POPs & $\mathrm{P}, \mathrm{Pa}$ & $\log \mathrm{K}_{\mathrm{o} / \mathrm{w}}$ & $\mathrm{K}, \Pi \mathrm{\Pi a} \cdot \mathrm{m}^{3} / \mathrm{mol}$ & $\mathrm{S}, \mathrm{mg} / \mathrm{L}$ \\
\hline \multirow{2}{*}{ OCPs } & $2 \cdot 10^{-5}-4^{7}$ & $3-6,9^{7}$ & $0,033-839,37^{7}$ & $7 \cdot 10^{-5}-31,4^{7}$ \\
& $1,3 \cdot 10^{-5}-0,067^{8}$ & & & \\
\hline \multirow{2}{*}{ PCBs } & $2,9 \cdot 10^{-9}-2,1^{8}$ & $3,75-11,20^{9}$ & $1,72-817,9^{9}$ & $1,2 \cdot 10^{-6}-5,5^{9}$ \\
& $5,2 \cdot 10^{-8}-2,04^{9}$ & $5,8-8,4^{10}$ & $2,2-28,1^{10}$ & $1,3 \cdot 10^{-6}-0,27^{10}$ \\
\hline \multirow{3}{*}{ PAHs } & $7,51 \cdot 10^{-7}-14,4^{8}$ & $3,35-7,19^{12}$ & $5,9 \cdot 10^{-3}-56,2^{12}$ & $2,6 \cdot 10^{-4}-30,6^{12}$ \\
& $1,84 \cdot 10^{-8}-14,2^{11}$ & $3,26-6,5^{13}$ & $0,027-46^{13}$ & $2,6 \cdot 10^{-4}-31^{13}$ \\
\hline
\end{tabular}

Notes: $P$ is the saturated vapor pressure of the solid; $\log K_{o / w}$ is the logarithm of the distribution constant in the octanol/water system (hydrophobicity coefficient); $K$ is Henry adsorption constant; $\mathrm{S}$ is solubility in water.

In recent years, investigations on monitoring and disperse-phase distribution of POPs in the Dnieper River's surface water ${ }^{19-22}$ were carried out. By the term-"disperse-phase distribution" distribution of POPs between water phase (water-soluble state), the fine fraction of suspended particulate matter (SPM) (pore size $>0,45$ and $<16-24 \mu \mathrm{m}$ ) and the rough fraction of SPM $(>16-24 \mu \mathrm{m})$ was meant. This paper aimed to generalize the results from these publications, their supplement, and the determination of regularities of disperse-phase distribution of OCPs, PCBs, and PAHs.

\section{Experimental}

A sampling of surface water was carried out from the Dnieper River (along the left bank) near Kyiv from 2011 to 2019. The main monitoring points were located along the coast of the Darnytskyi district of Kyiv. They were also located up the River opposite Vyshgorod and at the Desna River's confluence into the Dnieper River. Sampling schemes are given in papers ${ }^{20,23}$.

The concentrations of the following compounds were determined: OCPs $-\alpha-, \beta-, \gamma$-hexachlorocyclohexanes $(\mathrm{HCH})$, hexachlorobenzene (HCB), heptachlor, aldrin, 4,4'-dichlorodiphenyldichloroethylene (DDE), 4,4'-dichlorodiphenyldichlorohane (DDD), 4,4'dichlorodiphenyltrichloroethane (DDT); PCBs - 2,4'di- (number 8); 2,2',5-tri- (18); 2,4,4'-tri- (28); 2,4',5tri- (31); 2,2',5,5'-tetra- (52); 2,2',4,5'-tetra- (49); 2,2',3,5'-tetra- (44); 2,3',4,4'-tetra- (66); 2,2',4,5,5'- penta- (101); 2,2',4,4',5-penta- (99); 2,3,3',4',6-penta(110); 2,2',3,4',5',6-hexa- (149); 2,2',3,5,5',6-hexa(151); 2,3',4,4',5-penta- (118); 2,2',4,4',5,5'-hexa(153); 2,3,3',4,4'-penta- (105); 2,2',3,4,4',5'-hexa(138); 2,2',3,4',5,5',6-hepta- (187); 2,2',3,4,4',5',6hepta- (183); 2,2',3,3',4,4'-hexa- (128); 2,2',3,3',4,5,6'hepta- (174); 2,2',3,3',4,5',6'-hepta- (177); 2,2',3,4,4',5,5'-hepta- (180); 2,2',3,3',4,4',5-hepta(170); 2,2',3,3',4,5,5',6'-octa- (199); 2,2',3,3',4,4',5,6octa- (195); 2,2',3,3',4,4',5,5'-octa- (194); 2,2',3,3',4,4',5,5',6-nona- (206); 2,2',3,3',4,4',5,5', 6,6'-deca (209); PAHs-naphthalene (Nap), acenaphthylene (Acy), acenaphthene (Ace), phenanthrene (Phe), anthracene (An), fluoranthene (Flu), pyrene (Pyr), benzo(a)anthracene (BaA), chrysene (Chr), benzo(b)fluoranthene (BbF), benzo(k)fluoranthene $(\mathrm{BkF})$, benzo(a)pyrene $(\mathrm{BaP})$, dibenzo(a,h)anthracene (DahA), benzo(ghi)perylene (BghiP), indeno(1,2,3-cd)pyrene (InD).

The methodology of determining OCPs, PCBs, and PAHs in natural water is schematically presented in Figure 1. Let's consider all stages in detail.

Sampling was carried out in the Dnieper River at the depth 0,5-1 $\mathrm{m}$ by bathometer. Collected samples were acidified to $\mathrm{pH} 1,0-2,0$ by hydrochloric acid. A specific volume of water was allowed to go sequentially through rough (pore size 16-24 $\mu \mathrm{m}$, Whatman, Cat. No. 1821150), fine $(0,45 \mu \mathrm{m}$, Millipore, Cat. No. HVLP04700) filters, and porous polymer sorbents (PPS) as follows XAD-2, XAD-7, and XAD-16. 
After filtration rough and fine filters were dried to airdry condition. Then rough filters were homogenized and placed in the Soxhlet apparatus for extraction of organic compounds. Fine filters were not homogenized, and after drying, they were placed in the Soxhlet apparatus for extraction of organic compounds. Extraction of organic compounds from filters was carried out by a mixture of organic solvents acetone: hexane $(1: 1$, volume $-140 \mathrm{~mL})$ in the Soxhlet apparatus for $16 \mathrm{~h}$.

Elution of organic compounds from sorbents XAD-2, XAD-7, and XAD-16 was performed sequentially by acetone and hexane (1:1, total volume of $140 \mathrm{~mL})$. To an acetone-hexane solution of analytes, water (volume-140 $\mathrm{mL}$ ) was added. After intensive agitation and subsequent stratification water-acetone layer was disposed.

In analyzing OCPs and PCBs, hexane solution was processed by concentrated sulphuric acid and (or) oleum for disposal of redundant organic substances. The cleared hexane solution was washed by three amounts of MilliQ Water (volume of each $-30 \mathrm{~mL}$ ) with the addition of sodium hydrogencarbonate (mass concentration $-3 \%$ ).

After that, a hexane solution of OCPs and PCBs was dried by freshly calcined sodium sulfate and evaporated to a specific volume. An aliquot of the final extract was injected into the gas chromatograph. Identification and determination of OCPs and PCBs were performed by gas chromatography/mass spectrometry (GC/MS) and gas chromatography/ electron-capture detection (GC/ECD) respectively to previously developed methodology ${ }^{3}$.

In analyzing PAHs after disposal of the water-acetone layer, hexane extract was dried by freshly calcined sodium sulfate and evaporated to a specific volume. An aliquot of the final extract was injected into the liquid chromatography. Identification and determination of PAHs were performed by highperformance liquid chromatography with fluorescence detection (HPLC/FD).

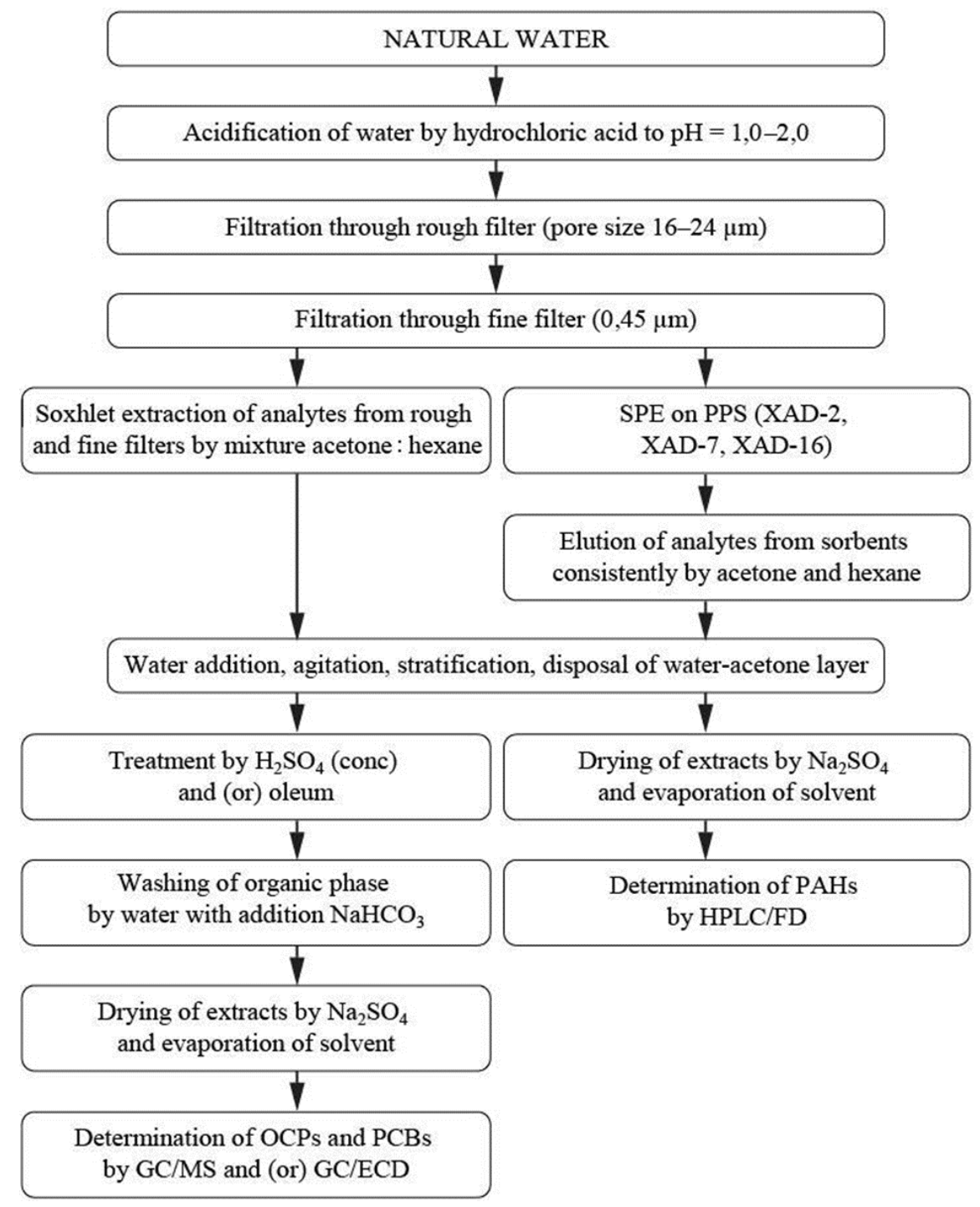

Figure 1. Scheme of investigation of OCPs, PCBs, and PAHs in the natural water 
GC/MS procedure. OCPs and PCBs were measured by GC/MS System (Agilent Technologies, Inc.) in the SCAN and SIM mode on an Agilent GC6890N coupled to MSD5975 Inert XL and Autoinjector 7683B.

Pure concentrates of OCPs and PCBs with a volume of $1 \mu \mathrm{L}$ were injected with a Hamilton syringe into the gas chromatograph's PTV injector without splitting the flow (splitless for $1 \mathrm{~min}$ ).

Chromatographic conditions in the SCAN and SIM mode: column-HP-5MSI or HP-5MS (5\% phenyl methylsiloxane $)(30 \mathrm{~m} \times 0,25 \mathrm{~mm} \times 0,25 \mu \mathrm{m})$; carrier gas -helium, linear rate $-37,0 \mathrm{sm} / \mathrm{s}$, volume rate $-1 \mathrm{~mL} / \mathrm{min}$ with temperature correction of the carrier gas flow rate; initial pressure at the inlet to the capillary column (in the PTV injector) $-8,23$ psi $(56 \mathrm{kPa})$; gradient - from 60 to $160^{\circ} \mathrm{C}$ with a heating rate of $25^{\circ} \mathrm{C} / \mathrm{min}$, from 160 to $300^{\circ} \mathrm{C}-10^{\circ} \mathrm{C} / \mathrm{min}$ and isothermic period at $300^{\circ} \mathrm{C}-5 \mathrm{~min}$ (chromatography time $-23 \mathrm{~min}$ ). Mass spectrometric data collection began 6 min after injecting the sample into the gas chromatograph injector (Solvent delay $6 \mathrm{~min}$ ).

Mass spectrometric conditions: detector parameters SCAN or SIM modes at EI $(70 \mathrm{eV})$, mass spectra were recorded with an electron multiplier at a voltage of $0,9-1,4 \mathrm{kV}$ and a pressure of $210^{-5} \mathrm{~Pa}$ in the source area ions in the mass range with $\mathrm{m} / \mathrm{z} 34-550 \mathrm{amu}$. The interface, quadrupole, and ion source temperatures are $250,150-200$ and $230^{\circ} \mathrm{C}$, respectively.

The determination of OCPs and PCBs was carried out in the SIM mode with mass selective detection by characteristic ions for these compounds with $\mathrm{m} / \mathrm{z}$ : 109, 181, $219(\alpha-, \beta-, \gamma-, \delta-\mathrm{HCH}), 100,135,272$ (heptachlor), 66, 220, 263 (aldrin), 176, 246, 248 (4,4'-DDE), 165, 235, 237 (4,4'-DDD, 4,4'-DDT) and 256, 258, 260 (trichloro-), 290, 292, 294 (tetrachloro-), 324, 326, 328 (pentachloro-), 358, 360, 362 (hexachloro-), 392, 394, 396 (heptachloro-), 426, 428, 430 (octachloro-), 460, 462, 464 (nonachloro-).

GC/ECD procedure. OCPs and PCBs were determined by gas chromatography with an electron capture detector (GC/ECD) on HP GC5890 Series II with a single ECD. The sample of organic contaminants $(1 \mu l)$ was injected into the chromatograph's injector splitless by Hamilton syringe. Chromatography conditions: carrier gas nitrogen; inlet pressure $50 \mathrm{kPa}$; oven temperature program - from $60^{\circ} \mathrm{C}$ to $270^{\circ} \mathrm{C}, 8^{\circ} \mathrm{C} / \mathrm{min}$ rate, then isothermally at $270^{\circ} \mathrm{C}$ for $15 \mathrm{~min}$; column - HP-5 $(25 \mathrm{~m} \times 0,25 \mathrm{~mm} \times 0,32 \mu \mathrm{m})$. Make up gas - nitrogen; inlet pressure $-100 \mathrm{kPa}$; rate $-40 \mathrm{ml} / \mathrm{min}$; anode purge $-4 \mathrm{ml} / \mathrm{min}$. Injector $-280^{\circ} \mathrm{C}$. Detector $-300^{\circ} \mathrm{C}$.

In papers 3,16,24-26, determining OCPs 14, 24, 26 and PCBs ${ }^{14,16,25,26}$ are presented in more detail.

HPLC/FD procedure. Identification and determination of PAHs in the obtained concentrates was performed by high performance liquid chromatography by fluorescence detection (HPLC/FD). PAH concentrates were analyzed on a Waters Alliance with an E2695 separation module, 2998 photodiode arrow and 2475 multiwavelength fluorescent detector. Parameters: Merck column 150433 - 250×4,6 mm; sorbent - LiChrosorb RP-18, $5 \mu \mathrm{m}$; injected (autoinjector) volume - 50-100 $\mu \mathrm{l}$; mobile phase $-\mathrm{A}\left(\mathrm{CH}_{3} \mathrm{CN} / \mathrm{H}_{2} \mathrm{O}\right.$, v/v 4:5), $\mathrm{B}\left(\mathrm{CH}_{3} \mathrm{CN}\right)$; pump gradient - from $100 \%$ A to $100 \% \mathrm{~B}, 50 \mathrm{~min}$; then $\mathrm{B}-10 \mathrm{~min}$; temperature $-25^{\circ} \mathrm{C}$. Detection was carried out simultaneously on 4 channels with the following parameters: $\mathrm{A}-\lambda_{\mathrm{ex}}=256, \lambda_{\mathrm{em}}=370$; $\mathrm{B}-\lambda_{\mathrm{ex}}=260, \lambda_{\mathrm{em}}=420 ; \mathrm{C}-\lambda_{\mathrm{ex}}=275, \quad \lambda_{\mathrm{em}}=420$; $\mathrm{D}-\lambda_{\mathrm{ex}}=290, \lambda_{\mathrm{em}}=430 \mathrm{~nm}$; detector attenuation (photomultiplier gain) - 64; the polarity - positive; output signal - emission. The MDLs of this procedure for PAHs is $0,01 \mathrm{ng} / \mathrm{L}$ at the enrichment factor $(1,4-2,8) \cdot 10^{3}$.

In papers ${ }^{3,21,22}$, the determination of PAHs is presented in more detail.

Calibration of techniques for determination of OCPs, PCBs, PAHs was carried out on standard mixtures Supelco EPA Pesticides Mix 48858-U 10-60 $\mu \mathrm{g} / \mathrm{mL}$ in $\mathrm{MeOH}: \mathrm{CH}_{2} \mathrm{Cl}_{2}$ (98:2); Supelco EPA CEN PCBs Congener Mix 1 4-7927 $10 \mu \mathrm{g} / \mathrm{mL}$ in heptane; Supelco EPA 610 PAHs Mix 4-8743 100-2000 $\mu \mathrm{g} / \mathrm{mL}$ in $\mathrm{MeOH}: \mathrm{CH}_{2} \mathrm{Cl}_{2}$ (1:1), respectively.

The data obtained were evaluated with the help of the reference materials: Standard Reference Material (SRM) 1944 NIST (New York /New Jersey Waterway Sediment) and SRM 2977 NIST Mussel Tissue (Organic Contaminants and Trace Elements) and TEST MATERIAL (natural water sample).

Statistical treatment of the data was performed with the use of Pearson correlation analysis by computer program Statistical Package for the Social Sciences version 19 (SPSS, Inc., IBM Company, Chicago, IL).

\section{Results and discussion}

\subsection{Concentration of OCPs, PCBs and PAHs in surface water of the Dnieper River}

A significant part of the results on monitoring of OCPs, PCBs, and PAHs in surface water of the Dnieper River was obtained during the period 2011-2013. These results are presented in papers ${ }^{19-22}$. In 2014-2019 this research was continued. In this paper, overall results on monitoring OCPs, PCBs, and PAHs in the Dnieper River's surface water for the period 2011-2019 are summarized and generalized.

The total concentration of OCPs in surface water of the Dnieper River consisted of 1,4-17,1 ng/L. Among individual OCPs, isomers of $\mathrm{HCH}$ and DDT prevailed. Their total concentrations accounted for 0-6,43 and 1,26-15,76 ng/L, respectively. Among $\mathrm{HCHs}$, the highest concentrations were found for $\beta$ and $\gamma$-isomers: $0,11-5,75$ and $0,31-2,10 \mathrm{ng} / \mathrm{l}$. 
Determined high concentrations of the $\gamma$-isomer (lindane) compared to the $\alpha$-isomer may indicate this pesticide's fresh intakes. High levels of 4,4'-DDT $(0,09-11,60 \mathrm{ng} / \mathrm{L})$ were recorded, which in some samples essentially exceed the concentrations of its metabolites, 4,4'-DDE and 4,4'-DDD. This may indicate the recent emission of $4,4^{\prime}$-DDT into the aquatic environment of the Dnieper River Basin. The levels of heptachlor and HCB were not significant $(<1 \mathrm{ng} / \mathrm{L})$. Aldrin was not identified in the great majority of samples.
Figure 2 presents the average annual total levels of OCPs in the Dnieper River's surface water during 2011-2019. It was shown that the whole level of OCPs did not change significantly and amounted to approximately $10 \mathrm{ng} / \mathrm{L}$. A more accurate mathematical processing of the average values over the years was carried out. The average value of the total amount of OCPs for this period was 9,8 $\pm 2,5$ $\mathrm{ng} / \mathrm{L}$. The relative value of the standard deviation is $25,5 \%$.

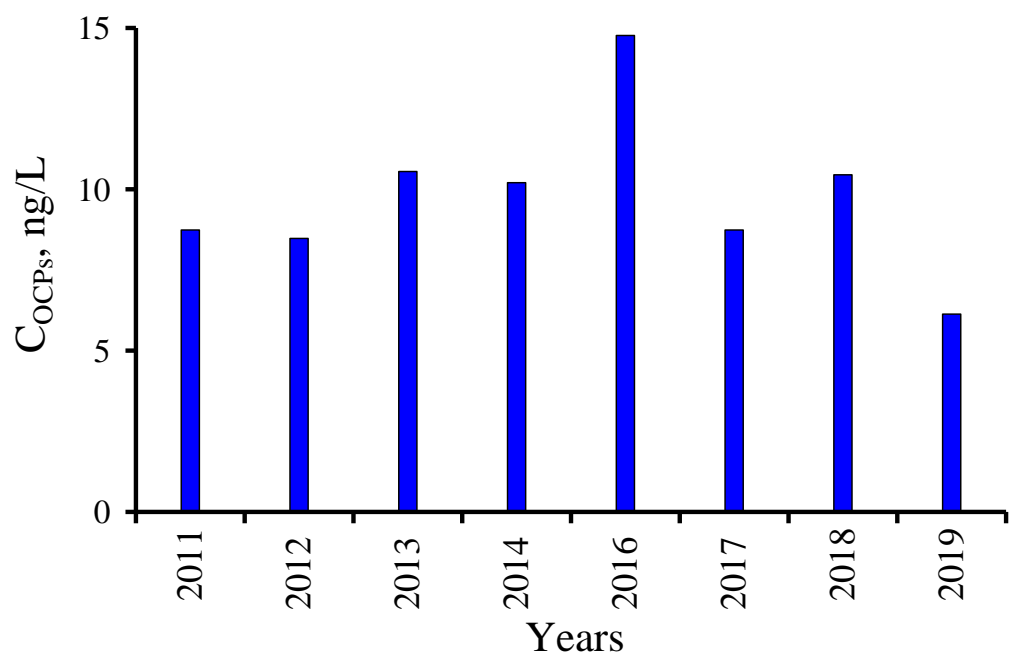

Figure 2. Average annual total concentrations of OCPs in surface water of the Dnieper River during 2011-2019

The total concentration of PCBs (29 congeners) in the Dnieper River's surface water accounted for 2,8-57,2 ng/L. Meanwhile, congeners with many chlorine atoms 4-6 prevailed. Thus, portions of tetra, penta- and hexa-PCBs accounted for, on average, 38, 20 , and $29 \%$ of the total level. Percentages of PCBs containing two, three, and seven chlorine atoms were not significant (less than 10\%).
As shown in Figure 3, high total PCBs $(\geq 40 \mathrm{ng} / \mathrm{L}$ ) levels were determined for water samples of 2013. In water samples collected in 2011 and 2016, total levels of PCBs did not exceed $10 \mathrm{ng} / \mathrm{L}$. The average value of the total amount of PCBs for this period was $22,4 \pm$ $12,8 \mathrm{ng} / \mathrm{L}$. The relative value of standard deviation is $57,1 \%$.

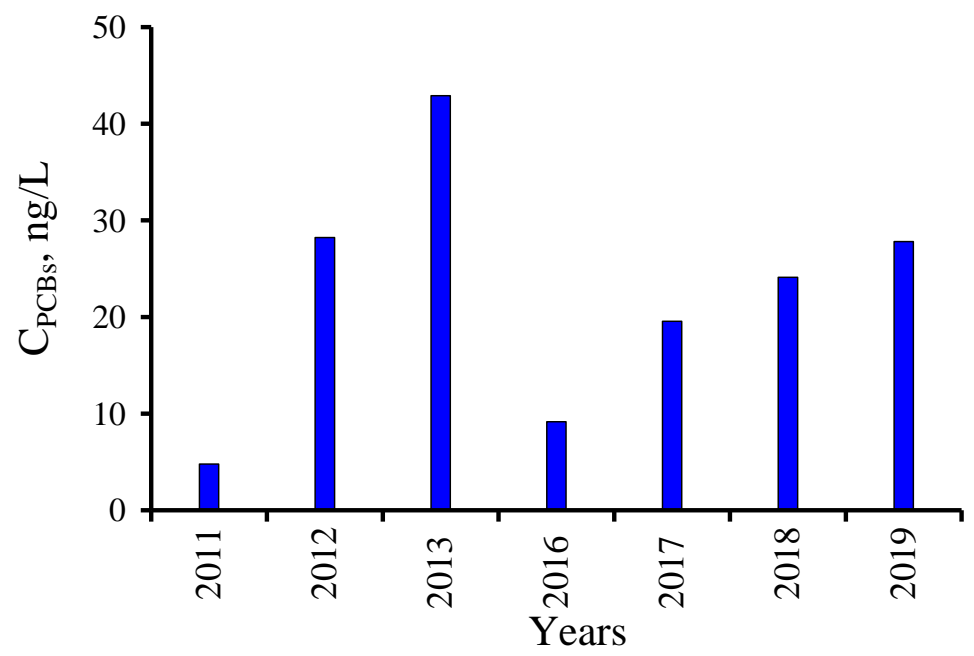

Figure 3. Average annual total concentrations of PCBs in surface water of the Dnieper River during 2011-2019

The total concentration of 16 priority PAHs in the Dnieper River's surface water consisted of 7,5-378,6 ng/L. Among individual PAHs, naphthalene, phenanthrene, fluoranthene, and benzo(ghi)perylene predominated. Some samples' concentrations were as high as 194,5; 142,5; 55,7 and 87,6 ng/L, respectively. Levels of the most hazardous PAHs, such as benzo(a)pyrene and dibenzo(a,h)anthracene, 
accounted for $0,05-1,59$ and $0,09-1,56 \mathrm{ng} / \mathrm{L}$, respectively.

In general, the sum of PAHs exceeded total levels of OCPs and PCBs by one order of magnitude. High total PAHs $(\geq 200 \mathrm{ng} / \mathrm{L})$ levels were recorded in 2012, 2013, 2016, 2017, and 2019 (Figure 4). In 2011 and
2014, concentrations of PAHs were low (in an amount up to $15 \mathrm{ng} / \mathrm{L}$ ). The average value of the sum of PAHs for this period was $174,7 \pm 105,3 \mathrm{ng} / \mathrm{L}$. Excluding 2011 and 2014 , it was $228,8 \pm 38,9 \mathrm{ng} / \mathrm{L}$. The relative values of the standard deviation are 60,3 and $17,0 \%$, respectively.

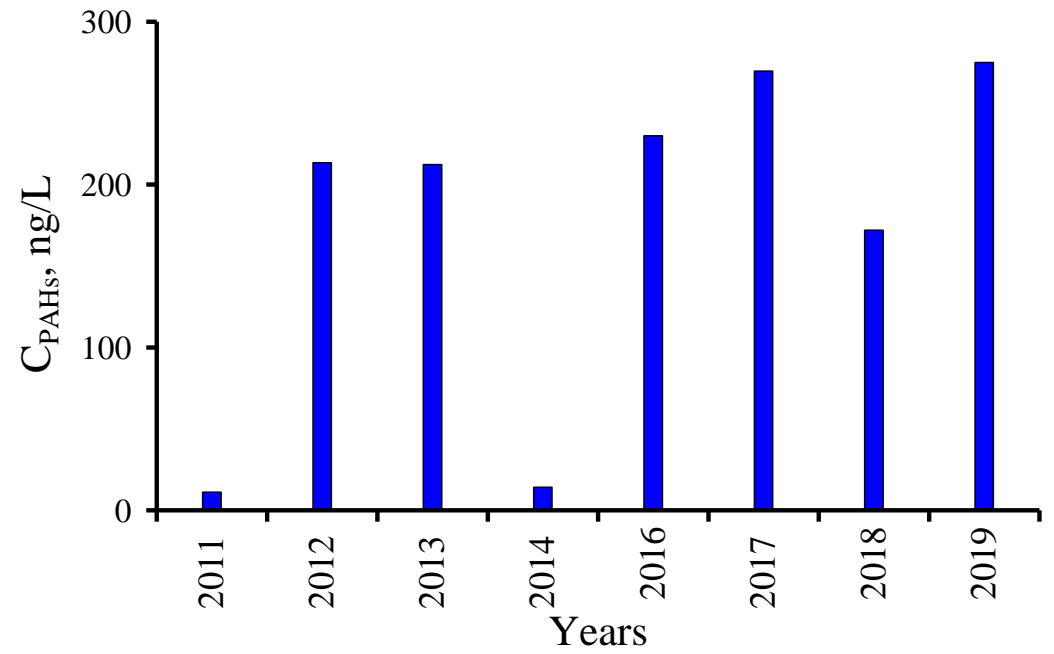

Figure 4. Average annual total concentrations of PAHs in surface water of the Dnieper River during 2011-2019

Reported pollution levels are medium at a global scale ${ }^{27-31}$. In China and other Asian countries, the concentration of POPs is much higher. For example, total concentrations of OCPs, PCBs, and PAHs in the water of Tonghui River (Beijing, China) varied from 134,9 to $3788 \mathrm{ng} / \mathrm{L}$, from 31,58 to $344,9 \mathrm{ng} / \mathrm{L}$ and from 192,5 to $2651 \mathrm{ng} / \mathrm{L}$, respectively ${ }^{27}$. Very high concentrations of PAHs $(0,06-84,21 \mu \mathrm{g} / \mathrm{L})$ were identified in the water of the Gomti River (India) ${ }^{28}$. Lower concentrations are observed in the water of European rivers. For instance, in the water of the Tiber River (Italy) total concentrations of OCPs, PCBs, and PAHs accounted for 0,07-7,04; 0,54-74,7; and 10,3-951,6 $\mathrm{ng} / \mathrm{L}$, respectively ${ }^{29,30}$. Levels of PCBs in the water of high altitude Alpine Lakes Muzelle and Plan Vianney are even lower (less than $1 \mathrm{ng} / \mathrm{L})^{31}$.

Note that according to the results obtained in the 1990s in Ukraine, the total concentrations of PCBs in water of the Dnieper River (Kyiv region) were approximately at the same level and were in the range of $15,8-41,0 \mathrm{ng} / \mathrm{L}$. The average values of the total PCBs were $24,3 \pm 14,3 \mathrm{ng} / \mathrm{L}^{3,16,25,26}$. The total concentrations of PCBs in the water of the Desna River (Kyiv region) were lower and were in the range of 3,2-9,3 ng/L ${ }^{3,16,25,26}$, on average $-6,5 \pm 2,5 \mathrm{ng} / \mathrm{L}$.

In the same period, the sum of OCPs and the sum of PCBs in surface water of the middle part of the Dnieper River (region of Dnepropetrovsk, Zaporozhye, Nikopol) were in the range 12,1-27,6 and 4,9-9,3 $\mathrm{ng} / \mathrm{L}^{3,24}$. On average, they were $17,9 \pm 8,4$ and $6,7 \pm 1,7 \mathrm{ng} / \mathrm{L}$.

In 2010-2011 in surface water of the Dnieper River and Desna River (district of Kyiv region), low concentrations of PAHs were determined. In total, they amounted to $5,9-28,3 \mathrm{ng} / \mathrm{L}$, on average$13,1 \pm 7,2 \mathrm{ng} / \mathrm{L}^{3,17}$. In 2012, the concentration of PAHs in the Dnieper River basin was higher; in total, they reached values of $133,0 \mathrm{ng} / \mathrm{L}^{17}$.

Maximum permissible concentration and safe exposure level for OCPs (DDT and its metabolites, aldrin, lindane, etc.) and PCBs in aquaculture water (fishery) should be as low as $10 \mathrm{ng} / \mathrm{L}^{32}$. The average value of the total amount of OCPs for the investigated period did not exceed this level. Most of the samples tested showed higher levels of PCBs.

According to the Directive of the EC Council ${ }^{33}$ the permissive concentrations of individual compounds of PAHs in surface water have been lowered and correspond to $0,05 \mu \mathrm{g} / \mathrm{L}$ for benz(a)pyrene, $0,03 \mu \mathrm{g} / \mathrm{L}$ for the sum of benz(b)fluoranthene, and benz $(\mathrm{k})$ fluoranthene, and $0,002 \mu \mathrm{g} / \mathrm{L}$ for the sum of benz(g,h,i)perylene and indeno(1,2,3-cd)pyrene. However, the total permissive concentration for PAHs was not provided.

In Ukraine, the regulatory document DSanPin 2.2,4171-10 in force provides for the permissive concentrations of benz $(a)$ pyrene in tap water and well water at the level $<0,005$ and $<0,002 \mu \mathrm{g} / \mathrm{L}$, respectively. However, for bottled waters and artesian water, such permissive concentrations have not been established yet ${ }^{34}$. The maximum permissive concentrations and safe exposure levels for PAHs in aquaculture water (fishery) were not established either ${ }^{32}$.

In comparison with standards established by the EC Council's Directive in the Dnieper River's surface 
water, higher concentrations of benz $(\mathrm{g}, \mathrm{h}, \mathrm{i})$ perylene were determined. Benz(a)pyrene, benz(b) fluoranthene, and benz(k)fluoranthene concentrations did not exceed acceptable levels.

3.2. Disperse-phase distribution of OCPs, PCBs, and PAHs in surface water of the Dnieper River

Results on the determination of the disperse-phase distribution of OCPs, PCBs and PAHs in surface water of the Dnieper River were obtained for 2013 and 2017. They reveal that more than half of these classes' surface water is associated with suspended particles in the Dnieper River's surface water.

Average water-soluble part of OCPs, parts on the rough and fine SPM fractions accounted for 32, 50, and $18 \%$, respectively. Figure 5 presents the average disperse-phase distribution of individual OCPs in surface water of the Dnieper River. The $\alpha-\gamma-\mathrm{HCH}$, and HCB were found predominantly in the water phase. Water-soluble parts of the remaining pesticides accounted for 19-31\%. These data confirm the need to examine SPM because the predominant part of OCPs is contained in the suspended particles.

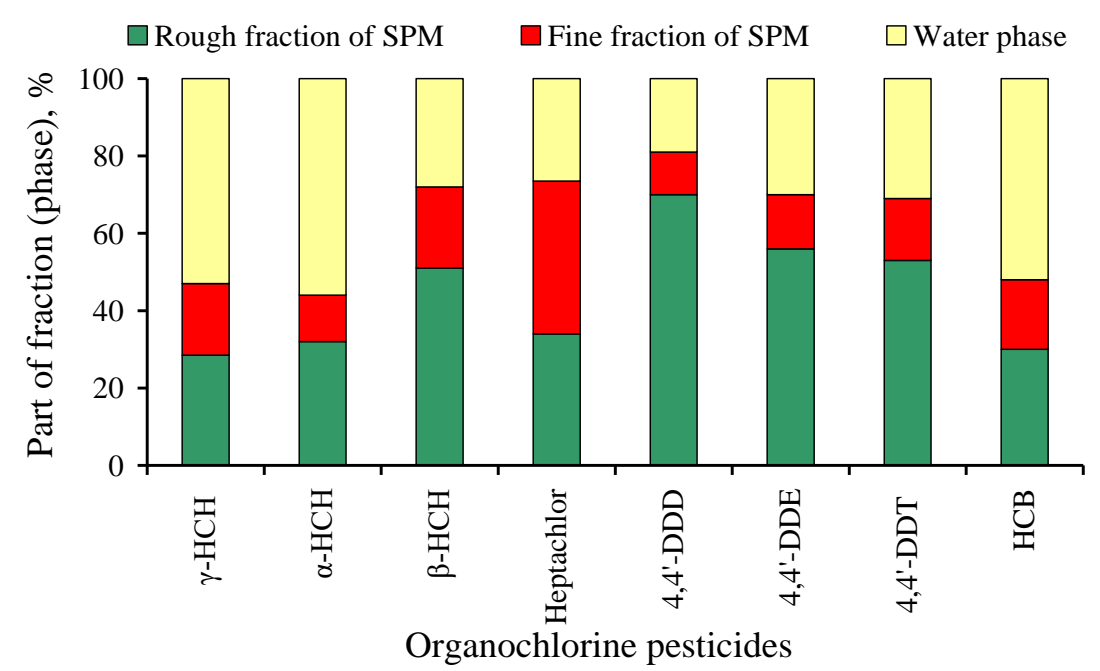

Figure 5. Disperse-phase distribution of OCPs in surface water of the Dnieper River

Almost half of PCBs (on average 42\%) is present in the water-soluble state. Average parts of the rough and the fine SPM fractions accounted for 34 and $24 \%$, respectively. Disperse-phase distribution of individual PCB congeners varies considerably (Figure 6). The water-soluble part of the congener decreases along with the increase in the number of chlorine atoms in the molecule. For instance, watersoluble parts of PCB $8\left(2,4^{\prime}-\right.$ di $)$ and PCB 180 $\left(2,2^{\prime}, 3,4,4^{\prime}, 5,5^{\prime}\right.$-hepta) consisted of 8 and $78 \%$, respectively. The most prevalent congeners with number of chlorine atoms 4-6 were evenly distributed between water and SPM.

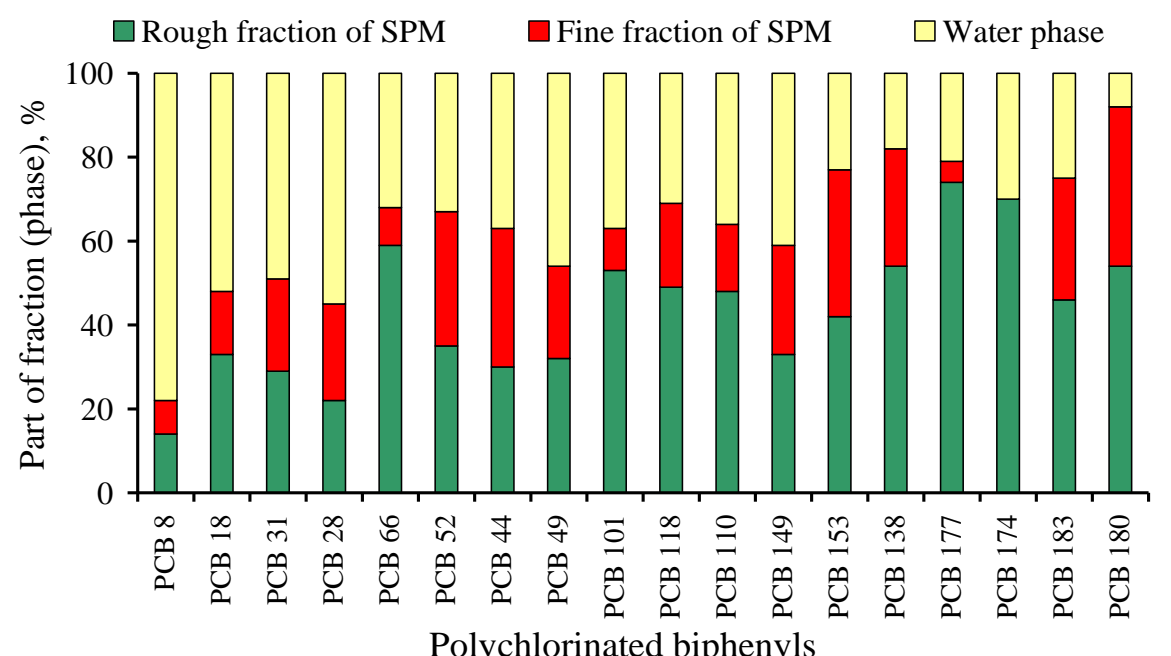

Figure 6. Disperse-phase distribution of PCBs in surface water of the Dnieper River

Average water-soluble part of PAHs, parts on the rough, and the fine SPM fractions accounted for 44, 37 , and $19 \%$, respectively. Only naphthalene was found among individual PAHs predominantly (on average $91 \%$ ) in the water phase. Water-soluble parts of other PAHs accounted for 6-28\% (on average- 
$16,6 \pm 7,9 \%$ ). Levels of water-soluble parts of the number of cycles in the molecule (Figure 7). individual PAHs decline together with the increase in

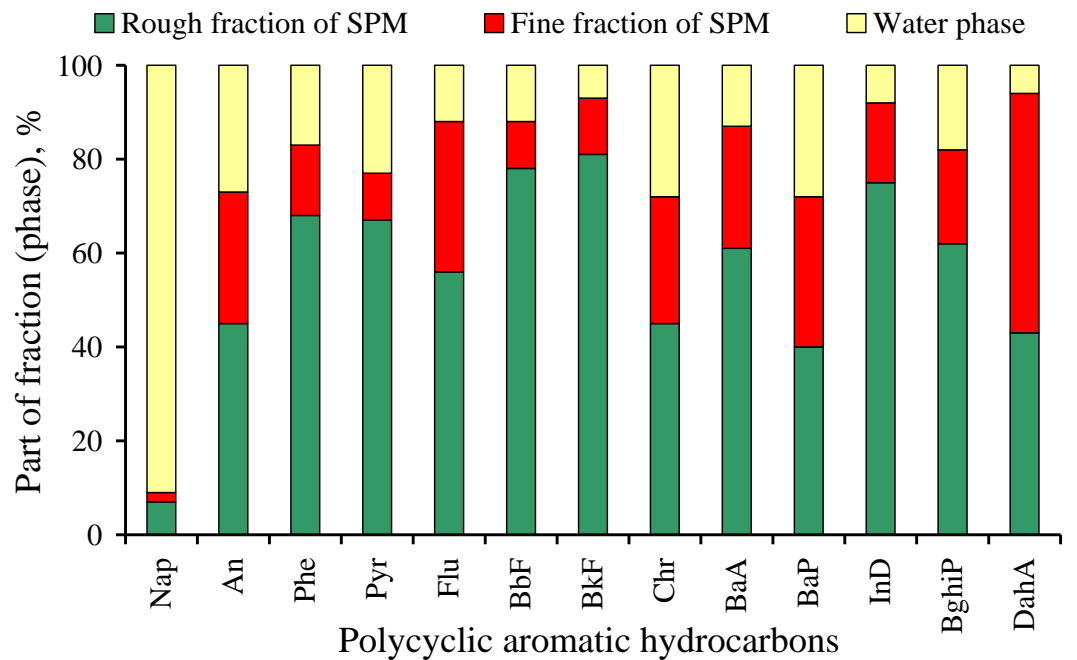

Figure 7. Disperse-phase distribution of PAHs in surface water of the Dnieper River

The presented results differ to some extent from the literary data. For example, water-soluble parts of OCPs and PCBs in the Yangtze River's water (China) were higher and accounted on average to 52 and $84 \%$, respectively ${ }^{35,36}$. In the Tiber River, the water-soluble parts of OCPs, PCBs, and PAHs accounted on average to 54,16 , and $45 \%$, respectively ${ }^{29,30}$. In the Daliao River (China) the intermediate level of the watersoluble part of PAHs was much lower $(16 \%)^{37}$. This difference in the literary data may be related to the influence of many natural factors, such as salinity and alkalinity of water, SPM concentration, chemical nature and size of suspended particles, the content of natural organic compounds (humic and fulvic acids, high molecular carbohydrates), $\mathrm{pH}$, the temperature of the water system.

\subsection{Relationship between the disperse-phase distribution of individual OCPs, PCBs, and PAHs and coefficient of hydrophobicity}

Disperse-phase distribution of individual organic ecotoxicants is attributable to their physical-chemical properties, including hydrophobicity expressed as the octanol-water partition logarithm $\left(\log \mathrm{K}_{\mathrm{o} / \mathrm{w}}\right)$. For the Dnieper River relationship between the dispersephase distribution of individual OCPs, PCBs, PAHs, and hydrophobicity coefficient has been identified for surface water of the Dnieper River.

The relationship between the disperse-phase distribution of individual OCPs and the coefficient of hydrophobicity was shown in Figure 8. The watersoluble part of HCB was not considered because this compound considerably differs in properties from other OCPs.

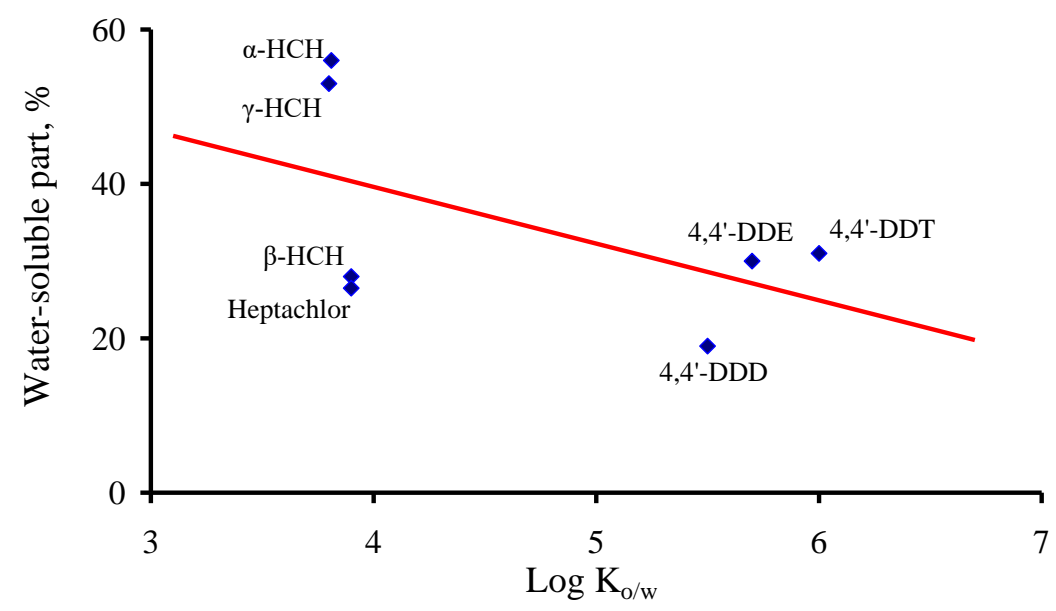

Figure 8. Relationship of water-soluble part of individual OCPs on $\log \mathrm{K}_{\mathrm{o} / \mathrm{w}}(\mathrm{r}=-0,532, \mathrm{p}=0,219)$

The coefficient of correlation ( $r$ ) and probability criterion (p) were calculated. It was found that $r=-0,5320, p=0,219$. Thus, the coefficient of this correlation is quite low, and the correlation is not relevant. This is because OCP's group consists of compounds with different chemical nature.

A more evident correlation was observed between the disperse-phase distribution of individual PCBs and coefficient of hydrophobicity (Figure 9) with the 
correlation coefficient and the probability criterion $r=-0,846, p=0,00001$, respectively. Considering the value of $\log \mathrm{K}_{\mathrm{o} / \mathrm{w}}$ of $\mathrm{PCB}$, congeners of the dispersephase distribution can be evaluated.

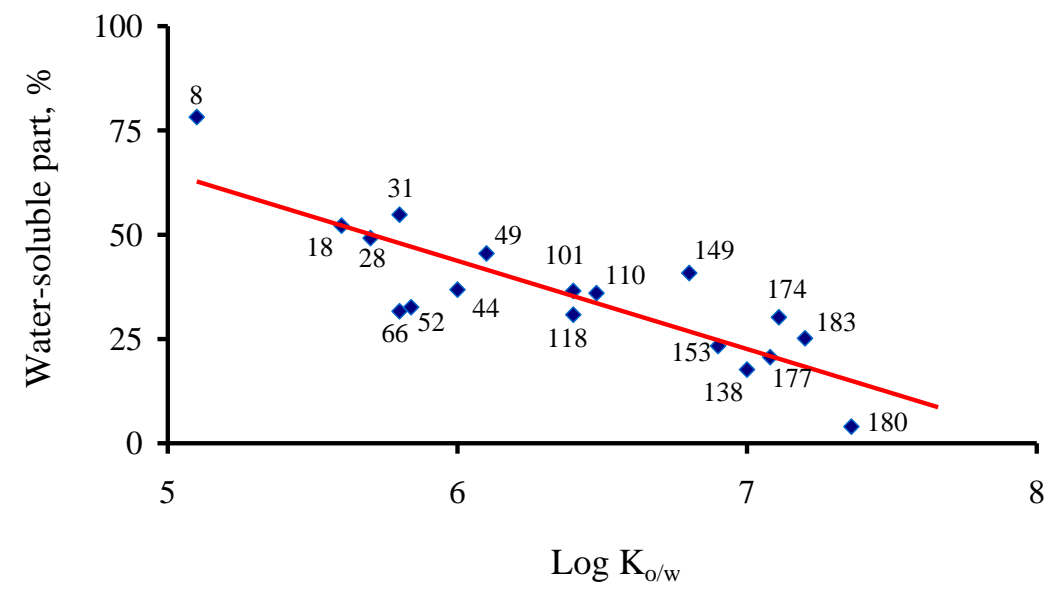

Figure 9. Relationship of water-soluble part of individual PCBs on $\log \mathrm{K}_{\mathrm{o} / \mathrm{w}}(\mathrm{r}=-0,846, \mathrm{p}=0,00001)$. Congeners of PCBs were labeled with numbers

Figure 10 presents the relationship between the disperse-phase distribution of individual PAHs and the coefficient of hydrophobicity. This relationship is characterized by high coefficient of correlation $(\mathrm{r}=-0,714)$ and is relevant $(\mathrm{p}=0,006<0,5)$.

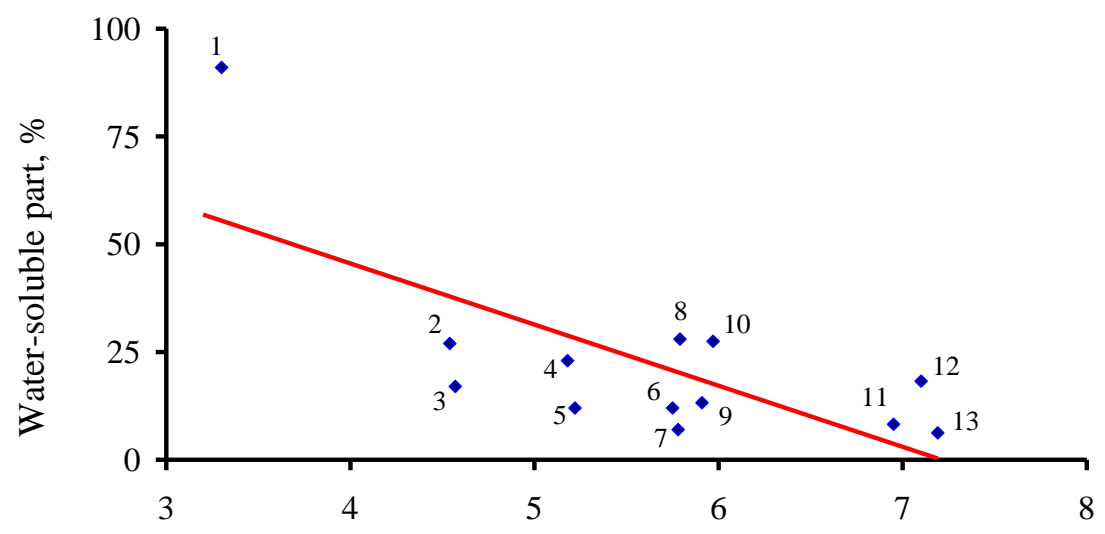

$\log \mathrm{K}_{\mathrm{o} / \mathrm{w}}$

Figure 10. Relationship of water-soluble part of individual PAHs on $\log \mathrm{K}_{\mathrm{o} / \mathrm{w}}(\mathrm{r}=-0,714, \mathrm{p}=0,006)$. PAHs were labeled with numbers: 1 - Nap, 2 - An, 3 - Phe, 4 - Pyr, 5 - Flu, 6 - BbF, 7 - BkF, 8 - Chr, $9-\mathrm{BaA}, 10-\mathrm{BaP}$, 11 - InD, 12 - BghiP, 13 - DahA

\section{Conclusion}

The results of monitoring POPs in the Dnieper River's surface water are presented for 2011-2019. Total concentrations of OCPs, PCBs and PAHs consist of 1,4-17,1;2,8-57,2; and 7,5-378,6 ng/L, respectively. The average concentrations of OCPs, PCBs, and PAHs for this period were $9,8 \pm 2,5 ; 22,4 \pm 12,8$; $228,8 \pm 38,9$ ng/L, respectively. These levels are medium on a global scale.

Disperse-phase distribution of OCPs, PCBs, and PAHs in surface water of the Dnieper River was determined. It was shown that more than half of the compounds of these classes are associated with suspended particles. Average water-soluble parts of OCPs, PCBs, and PAHs accounted for 32, 42, and $44 \%$, respectively. Only $\alpha-, \gamma-\mathrm{HCH}, \mathrm{HCB}, \mathrm{PCB}$ 8 (2,4'-di), PCB 18 (2,2',5-tri-), PCB 28 (2,4,4'-tri-) and naphthalene were found predominantly in water phase. Their water-soluble parts accounted for 56,53 , $58,78,52,55$ and $91 \%$, respectively.

The relationship between the disperse-phase distribution of individual OCPs, PCBs, PAHs, and hydrophobicity coefficient has been identified. The clearest reliable relevant correlations were obtained for PCBs and PAHs with the correlation coefficient and the probability criterion $r=-0,846, p=0,00001$ and $\mathrm{r}=-0,714, \mathrm{p}=0,006$, respectively.

\section{References}

1- S.A. Eqani, R.N. Malik, A. Cincinelli, G. Zhang, A. Mohammad, A. Qadir, A. Rashid, H. Bokhari, K.C. Jones, A. Katsoyiannis, Uptake of organochlorine pesticides (OCPs) and polychlorinated biphenyls (PCBs) by river water 
fish: The case of River Chenab, Sci. Tot. Environ., 2013, 450-451, 83-91.

2- B.A.M. Bandowe, M. Bigalke, L. Boamah, E. Nyarko, F.K. Saalia, W. Wilcke, Polycyclic aromatic compounds (PAHs and oxygenated PAHs) and trace metals in fish species from Ghana (West Africa): Bioaccumulation and health risk assessment, Environ. Intern., 2014, 65, 135-146.

3- M.V. Milyukin, V.V. Goncharuk, Chemical monitoring of organic ecotoxicants in water systems; Naukova dumka: Kyiv, 2016, 312.

4- W. Xu, X. Wang, Z. Cai, Analytical chemistry of the persistent organic pollutants identified in the Stockholm Convention: A review, Analytica Chimica Acta, 2013, 790, 1-13.

5- L.H. Keith, The source of U.S. EPA's sixteen $\mathrm{PAH}$ priority pollutants, Polycyclic aromatic compounds, 2015, 1-14.

6- M.A. Williams, C. Salice, G. Reddy, Wildlife toxicity assessment for benzo[a]pyrene, Wildlife Toxicity Assessments for Chemicals of Military Concern, 2015, 24, 421-437.

7- L.R. Suntio, W.Y. Shiu, D. Mackay, J.N. Seiber, D. Glotfelty, Critical review of Henry's law constants for pesticides, Rev. Environ. Contam. Toxicol., 1988, 103, 1-59.

8- A. Delle Site, The vapor pressure of environmentally significant organic chemicals: a review of methods and data at ambient temperature, J. Phys. Chem. Ref. Data, 1997, 26, 157-193.

9- W.Y. Shiu, D. Mackay, A critical review of aqueous solubilities, vapor pressures, Henry's law constants, and octanol-water partition coefficients of the polychlorinated biphenyls,

J. Phys. Chem. Ref. Data, 1986, 15(2), 911-929.

10-M. Gdaniec-Pietryka, L. Wolska, J. Namiesnik, Physical speciation of polychlorinated biphenyls in the aquatic environment, Trends in Anal. Chem., 2007, 26, 1005-1012.

11-Y.D. Lei, R. Chankalal, A. Chan, F. Wania, Supercooled liquid vapor pressures of the polycyclic aromatic hydrocarbons, J. Chem. Eng. Data, 2002, 47, 801-806.

12-L. Eastcott, W.Y. Shiu, D. Mackay, Environmentally relevant physical-chemical properties of hydrocarbons: a review of data and development of simple correlations, Oil Chem. Pollut., 1988, 4, 191-216.

13-P.G.J. De Maagd, D.T.E.M. ten Hulscher, H. van den Heuvel, A. Opperhuizen, D.T.H.M. Sijm, Physicochemical properties of polycyclic aromatic hydrocarbons: aqueous solubilities, noctanol/water partition coefficients, and Henry's law constants, Environ. Toxicol. Chem., 1998, 17, 251-257.

14-J. Sangster, Octanol-water partition coefficients of simple organic compounds, J. Phys. Chem. Ref. Data, 1989, 18, 1111-1227.

15-V.V. Goncharuk, M.V. Milyukin, Evaluation of contamination level of Dnieper River basin by organic and inorganic toxicants, Bioavailability of Organic Xenobiotics in the Environment, Dordrecht, 1999, 64, 35-56.

16-M.V. Milyukin, Determination of isomericspecific composition of polychlorinated biphenyls in natural and drinking waters of Dnieper River basin in Kiev region using gas chromatography and mass-spectrometry, Role of Interfaces in Environmental Protection, Dordrecht, 2003, 24, 103-120.

17-M.V. Milyukin, V.V. Goncharuk, Chemical monitoring of organic ecotoxicants in aqueous systems, Journal of Water Chemistry and Technology, 2019, 41, 517-528.

18-W.L. Lockhart, C.G. Muir, P. Wilkinson, A. Yarechewski, B.N. Billeck, Chemical contaminants in fish and sediment core samples from the Dnipro river, Ukraine, 1994, Water Quality Research Journal of Canada, 1998, 33, 489-509.

19-M.V. Milyukin, M.V. Gorban, Monitoring and disperse-phase distribution of organochlorine pesticides in natural water, Methods and Objects Chem. Anal., 2016, 11, 25-30.

20-M.V. Milyukin, M.V. Gorban, M.M. Skrynnyk, Monitoring and disperse-phase distribution of polychlorinated biphenyls in natural water, Methods and Objects Chem. Anal., 2016, 11, 81-87.

21-M.V. Milyukin, M.V. Gorban, Monitoring and disperse-phase distribution of light polycyclic aromatic hydrocarbons in natural water, $\mathbf{J}$. Chromatogr. Soc. (Ukraine), 2016, 16(1-4), 5-13.

22-M.V. Gorban, M.V. Milyukin, Physical forms of distribution of heavy polycyclic aromatic hydrocarbons in natural water of Dnieper River in Kyiv region, Methods and Objects Chem. Anal., 2017, 12, 145-151.

23-K.T. Ho, I.M. Konovets, A.V. Terletskaya, M.V. Milyukin, A.V. Lyashenko, L.I. Shitikova, L.I. Shevchuk, S.O. Afanasiev, Y.G. Krot, K.Y. Zorina-Sakharova, V.V. Goncharuk, M.M. Skrynnyk, M.A. Cashman, R.M. Burgess, Contaminants, mutagenicity and toxicity in the surface waters of Kyiv, Ukraine, Marine Pollution Bulletin, 2020, 155, 111153.

24-M.V. Milyukin, I.V. Gogoman, Identification and determination of organochlorine pesticides in natural water of Dnieper River basin by gas chromatography and mass-spectrometry, Methods and Objects Chem. Anal., 2011, 6, 214-224.

25-M.V. Milyukin, Identification and determination of polychlorinated biphenyls in natural and drinking waters by gas chromatography and mass-spectrometry, Ukr. Chem. J., 2003, 69, 43-51.

26-M.V. Milyukin, Solid-phase extraction for the determination of semivolatile organic compounds in water by gas chromatography and massspectrometry, Ukr. Chem. J., 2005, 71, 93-104. 
27-Z. Zhang, J. Huang, G. Yu, H. Hong, Occurrence of PAHs, PCBs and organochlorine pesticides in the Tonghui River of Beijing, China, Environ. Pollut., 2004, 130, 249-261.

28-A. Malik, P. Ojha, K.P. Singh, Levels and distribution of persistent organochlorine pesticide residues in water and sediments of Gomti River (India) - a tributary of the Ganges River, Environ. Monit. Assess., 2009, 148, 421-435.

29-P. Montuori, S. Aurino, F. Garzonio, M. Triassi, Polychlorinated biphenyls and organochlorine pesticides in Tiber River and Estuary: Occurrence, distribution and ecological risk, Sci. Total Environ., 2016, 571, 1001-1016.

30-P. Montuori, S. Aurino, F. Garzonio, P. Sarnacchiaro, A. Nardone, M. Triassi, Distribution, sources and ecological risk assessment polycyclic aromatic hydrocarbons in water and sediments from Tiber River and estuary, Italy, Sci. Total Environ., 2016, 566, 1254-1267.

31-Y.M. Nellier, M.E. Perga, N. Cottin, P. Fanget, E. Naffrechoux, Particle-dissolved phase partition of polychlorinated biphenyls in high altitude alpine lakes, Environ. Sci. Technol., 2015, 49, 9620-9628.

32-The List of Fishery Normatives: Maximum Accessible Concentrations (MAC) and roughly safely levels of effects (RSLE) of harmful substances for water of water objects of fishery significance, Minrybkhoz Rossii: Moscow, 1997.
33-Directive 200/105/EC of the European Parliament and the Council of 16 December 2008 on environmental quality standards in the field of water policy, amending and subsequently repealing Council Directive 82/176/EEC, 85/513/EEC, 84/156/EEC, 84/491/EEC, 86/280/EEC, 2000/60/EEC, 2000/60/EC and amending 2000/60/EC of the European Parliament of the Council.

34-DSanPiN 2.2.4-171-10. Derzhavni Sanitarni Normy ta Pravyla "Gigienichni Vymohy do vody pytnoi, pryznachenoi dlya spozhyvannya lyudynoyu" (State Sanitari Standards and Rules Hygienic Requirements to Drinking Water Designed for Compsumption By Humans).

35-Z. Tang, Z. Yang, Z. Shen, J. Niu, Y. Cai, Residues of organochlorine pesticides in water and suspended particulate matter from the Yangtze River catchment of Wuhan, China, Environ. Monit. Assess., 2008, 137, 427-439.

36-L. Zhang, S. Shi, L. Dong, T. Zhang, L. Zhou, Y. Huang, Concentrations and possible sources of polychlorinated biphenyls in the surface water of the Yangtze River Delta, China, Chemosphere, 2011, 85, 399-405.

37-B. Zheng, L. Wang, K. Lei, B. Nan, Distribution and ecological risk assessment of polycyclic aromatic hydrocarbons in water, suspended particulate matter and sediment from Daliao River estuary and the adjacent area, China, Chemosphere, 2016, 149, 91-100. 